\title{
Predation risk during the early life history periods of fishes: separating the effects of size and age*
}

\author{
D. F. Bertram**, W. C. Leggett \\ McGill University, Department of Biology, 1205 Dr. Penfield Avenue, Montréal, Québec, Canada H3A 1B1
}

\begin{abstract}
We compared predation risk for fish which differed in age at metamorphosis but not in length, and for those which differed in length at metamorphosis but not in age, using laboratory-reared winter flounder Pleuronectes americanus. Pairs of fish were offered to individual predatory shrimp Crangon septemspinosa as prey in a series of laboratory predation trials. In the size experiments, prey length differed on average by $0.5 \mathrm{~mm}(8 \%)$, but age was identical. We could not detect a difference in the number of captures of 'small' and 'large' individuals in 104 trials where only 1 prey was consumed. In the age experiments, prey age differed by $9 \mathrm{~d}(18 \%$ on average), but length was virtually identical. We could not detect a difference in the number of captures of 'young' and 'old' metamorphosing individuals in 56 trials where only 1 prey was consumed. Moreover, time until capture did not vary with increasing age at metamorphosis over a range of $35+\mathrm{d}$. These results suggest that any differences in predation risk between fish which exhibit the range of ages and sizes at metamorphosis represented in our experiments are subtle and are potentially ecologically inconsequential. This work, combined with that of others, questions the validity of the inference that, for marine fishes, individuals which are largeat-age have a survival advantage during the early life history periods.
\end{abstract}

KEY WORDS: Predation nisk - Fishes - Size $\cdot$ Age $\cdot$ Metamorphosis

\section{INTRODUCTION}

The high larval mortality rates characteristic of marine fishes have focused attention on factors that affect survival during early life stages. Recently, fisheries scientists have placed emphasis on the identification of traits of larval fishes which may correlate with high survivorship (e.g. Crowder et al. 1992). Since predation is considered to be an important source of mortality during the larval stages of marine fishes (e.g. Bailey \& Houde 1989), many investigators have concentrated on larval traits which may reduce predation-

\footnotetext{
- Contribution to the programs of GIROQ (Groupe Interuniversitaire de Recherches Océanographiques du Québecl and the Huntsman Marine Science Centre

- Present address: Friday Harbor Laboratories, University of Washington, 620 University Road, Friday Harbor, Washington 98250 , USA
}

induced mortality. For example, it has been argued that, within a cohort, individuals which grow most rapidly during the larval period will have the lowest cumulative mortality due to predation (e.g. Chambers \& Leggett 1987, Houde 1987, Rice et al. 1987, 1993, Anderson 1988, Beyer 1989, Pepin 1989a, b, Luecke et al. 1990). The proposition depends upon the influence of growth rate on stage duration and the pattern of size- and age-specific survival. Larvae which grow most rapidly generally develop most rapidly and hence will be among the first individuals to undergo metamorphosis within a cohort (e.g. Chambers \& Leggett 1987). If mortality rates are size and growth-rate independent throughout the larval period, these fast-growing larvae will have a survival advantage simply because the duration of their larval period is minimized. Furthermore, it has been argued that mortality rates are generally size-dependent, both among (e.g. McGurk 1986) and within (e.g. van der Veer \& 
Bergman 1987, Pepin et al. 1992) aquatic species. Assuming that large size-at-age is beneficial, these fast-growing individuals will not only be exposed to predation for a shorter period, but also they will be less vulnerable to predation during that period. If true, the cumulative effect of these size and growth-rate advantages would lead to significantly higher survival to metamorphosis for fast-growing larvae. Consequently, considerable effort has been devoted to quantifying the 'size component' of larval mortality. The results of predation trials which demonstrate that larger larvae have a lower risk of mortality have been used to support the inference that, within a cohort or year class of larval fish, larger, faster-growing larvae will have a higher probability of survival (e.g. Folkvord \& Hunter 1986, Luecke et al. 1990). However, as Litvak \& Leggett (1992) note, most predation studies have confounded the effects of age and length by comparing older, larger fish with younger, smaller fish. In addition, evidence cited in support of the view that large size-at-age is beneficial has frequently been based upon a partial analysis of the predation event (Litvak \& Leggett 1992). The probability of being eaten, or gross vulnerability to predation, can be separated into 3 multiplicative probabilities: the probability of being encountered; the probability of being attacked; and the probability of being captured (e.g. O'Brien 1979 , Fuiman 1989). Most studies conducted to date have not offered predators a choice of prey sizes and have therefore examined only the capture success component (reviewed by Litvak \& Leggett 1992). In such experiments the probabilities of encounter and attack cannot be adequately addressed. Recently, 2 studies (Litvak \& Leggett 1992, Pepin et al. 1992) have overcome these shortcomings by examining predation risk in relation to length, for larvae of the same age, in experiments where predators were offered a choice between small and large prey. Both studies reported that small yolk sac capelin. Mallotus villosus had higher survival in trials with stickleback predators Gasterosteus aculeatus than did larger larvae of the same age.

The studies by Litvak \& Leggett (1992) and Pepin et al. (1992), which examine the effects of length for equal-aged individuals on vulnerability to predation, were confined to yolk sac and early first feeding larvae. This limits the ability to generalize about phenotype-specific survival during subsequent life history periods. Moreover, no study to date has examined predation risk for fish which differ in age but not in length. To address these issues we chose to determine if variation in length and age at metamorphosis affects risk of predation for winter founder Pleuronectes americanus.

In this study we examined the frequency at which fish, which differed in length at metamorphosis and in age at metamorphosis, were eaten. The experiments were designed to separate the effects of size and age on risk of predation and to offer predators a choice of prey which differed in size or age. Specifically, we tested the hypothesis that large fish will have a higher probability of survival than will small fish in predation trials in which the predator is offered a choice of prey sizes. In addition, we predicted that older fish will have a higher probability of survival in predation trials than will younger fish due to the possibility of a physiological trade-off between somatic growth and the development of mature function of tissues (see Ricklefs 1973, $1979 \mathrm{a}, \mathrm{b}$ for evidence from birds). If true, rapid growth and early metamorphosis could occur at the expense of developing the neuromuscular system (e.g. the network of neuromasts used for detecting and escaping from predators). Hence, one result of a relatively long larval duration could be that fish which metamorphose at older ages may be better able to avoid capture by predators than larvae which metamorphose at younger ages.

\section{METHODS}

Model species. Winter flounder Pleuronectes americanus was chosen as the model species because individuals of this species can be collected easily, and their larvae can be reared to metamorphosis and beyond in the laboratory. We focused on the metamorphic stage because metamorphosis is a period of high predation mortality for some flatfishes (e.g. van der Veer \& Bergman 1987, Bergman et al. 1989, van der Veer et al. 1990, 1991, Seikai et al. 1993). Metamorphosis in winter flounder can be easily scored. Length and age at metamorphosis in winter flounder are variable (Chambers \& Leggett 1987, Bertram et al. 1993). In addition, length at metamorphosis does not change with increasing age at metamorphosis in some populations of winter flounder (e.g. Bertram et al. 1993), thus facilitating comparisons of fish which differ in length but not in age at metamorphosis, and fish which differ in age but not in length at metamorphosis. A further advantage of studying vulnerability to predation at metamorphosis is that all experimental individuals should be at the same stage of morphological development.

We used the sand shrimp Crangon septemspinosa as the predator in our experiments. In the North and Wadden Seas, shrimp of the genus Crangon have been identified as important predators of recently metamorphosed European plaice (van der Veer \& Bergman 1987. Bergman et al. 1989, van der Veer et al. 1990), and flounder Platichthys flesus (van der veer et al. 1991). Shrimp of the genus Crangon have also been reported to co-occur with, and to prey on, juveniles of several other flatfish species that settle in shallow 
coastal waters over a broad geographic range (Japanese flounder Paralichthys olivaceus, Seikai et al. 1993; starry flounder Platichthys stellatus, S. Campana, Bedford Institute of Oceanography, Dartmouth, N.S., Canada V2Y 4A2, pers, comm,; winter flounder, Jeffries \& Terceiro 1985, D. F. Bertram pers. obs.).

Rearing protocol. The research was conducted at the Huntsman Marine Science Centre, St. Andrews, New Brunswick (N.B.), Canada, from 1990 to 1991. Rearing protocols in the 2 years were similar. Rearing protocols for the 1990 experiments are reported in Bertram et al. (1993). In May 1991, adult winter flounder were collected in a bottom trawl in Passamaquoddy Bay, N.B., and were held at ambient seawater temperature $\left(7\right.$ to $\left.8^{\circ} \mathrm{C}\right)$ until the females were ripe. Eggs from individual females were combined with sperm pooled from 3 males to create half-sib families. Fertilized eggs were placed in a slurry of diatomateous earth for $12 \mathrm{~h}$ following fertilization to prevent clumping. Incubation temperature was $7 \pm 0.5^{\circ} \mathrm{C}$. At approximately $24 \mathrm{~h}$ post-fertilization, the eggs were immersed in solutions containing penicillin $\left(0.0158 \mathrm{~g} \mathrm{l}^{-1}\right)$ and streptomycin $\left(0.02 \mathrm{~g} \mathrm{l}^{-1}\right)$ for $24 \mathrm{~h}$. Following treatment with antibiotics, filtered and UV-sterilized seawater was replaced every 2 to $3 \mathrm{~d}$ until hatching commenced at approximately $14 \mathrm{~d}$ post-fertilization.

In early June 1991, 400 larvae (1 d old) from each of 4 half-sib families (early group) were transferred to 4 aquaria (total $=16$ aquaria). After $10 \mathrm{~d}, 2$ more families (late group) were stocked similarly. Temperatures in the rearing aquaria were maintained at $10 \pm 0.5^{\circ} \mathrm{C}$. At weekly intervals, 2 to $3 \mathrm{l}$ of water was removed from each aquarium and replaced with UV sterilized, filtered seawater. Dead larvae were removed regularly from the tank bottoms by siphoning.

Larvae were fed Brachionus sp. at $2 \mathrm{ml}^{-1} \mathrm{~d}^{-1}$ until the end of Week 7. These rotifers were cultured using Isochrysis and Chaetoceros spp. Rotifers were provided with Microfeast artificial plankton (Provesta Corporation) for $24 \mathrm{~h}$ prior to being fed to larvae to enhance their nutritional quality. From the end of Week 5 onwards, larvae were also offered Artemia nauplii $\left(0.25 \mathrm{ml}^{-1} \mathrm{~d}^{-1}\right)$. These nauplii were also enriched with Microfeast for $24 \mathrm{~h}$ prior to use.

Experiments. To standardize the developmental stage of fish used in our experiments, we used only fish whose left eye had just crossed the midline on its migration to the right side of the body (hereafter referred to as metamorphs). These metamorphs typically rested on the bottom of rearing tanks. Standard lengths of metamorphs were measured using a microscope fitted with an ocular micrometer. Fish were not anaesthetized at any time. In 1990, individual metamorphs were transferred to each experimental container $24 \mathrm{~h}$ before the trial commenced. Experimental containers were made of black plastic, were $34 \mathrm{~cm}$ in diameter and held $7 \mathrm{l}$ of water. In 1990, the containers had no substrate; in 1991, white sand was used as a substrate. (Note that metamorphs did not bury themselves in the sand although predators often did so when resting; see also Seikai et al. 1993.) Experimental containers were stocked with Artemia nauplii $\left(0.25 \mathrm{ml}^{-1} \mathrm{~d}^{-1}\right)$. In 1991, pairs of fish chosen for predation trials (see below) were transferred to each of the experimental arenas (which contained no food) at least $1 \mathrm{~h}$ before the trials commenced. Although capturing, measuring and transporting of metamorphs may induce some stress, we assumed that the effects of these treatments were the same for both fish in each of the experimental pairs.

Preliminary trials confirmed that the water depth $(8 \mathrm{~cm})$ in the experimental containers did not constrain prey mobility since the escape response was typically in the horizontal rather than the vertical plane. The containers provided sufficient space for escape responses because the escape distance for winter flounder in the size range used is small (2 to $4 \mathrm{~cm}$; Williams \& Brown 1992) relative to the container diameter. The densities of metamorphs in the experimental containers $\left[1\right.$ ind. $0.09 \mathrm{~m}^{-2}$ (11 ind. $\mathrm{m}^{-2}$ ) in 1990, and 2 ind. $0.09 \mathrm{~m}^{-2}$ (22 ind. $\mathrm{m}^{-2}$ ) in 1991, see below] exceeded the maximum density (4 ind. $\mathrm{m}^{-2}$ ) observed in the field for juvenile winter flounder (D. F. Bertram pers. obs) and European plaice (van der Veer et al. 1990). These densities were chosen to ensure encounters between predator and prey, while providing sufficient space for prey escape. The density of Crangon septemspinosa in the trials [1 ind. $0.09 \mathrm{~m}^{-2}$ (11 ind. $\left.\mathrm{m}^{-2}\right)$ ] were within the range of densities observed at our field site (2 to 12 ind. $\mathrm{m}^{-2}$; D. F. Bertram pers. obs.).

The predation trials were initiated at sunset because sand shrimp are crepuscular (Wilcox \& Jeffries 1974). Individual trials commenced when the shrimp predator was added to an experimental arena containing prey. The trials were conducted in a room illuminated by dim red light. At regular intervals ( 3 to $4 \mathrm{~h}$ in 1990, $2 \mathrm{~h}$ in 1991) observations were made with the aid of a red penlight. In 1990, the individual trials were terminated, and the duration of the trial recorded, either when the fish in each container was consumed, or the predator molted. In 1991, the individual trials were terminated (by removal of the predator) when 1 fish had been eaten or after $40 \mathrm{~h}$ had passed, whichever came first. In both years, time until capture was assumed to occur at the midpoint between the last observation at which the fish was still alive and the time at which it was missing. Survivors of the 1991 predation trials were measured or videotaped (see below) within $12 \mathrm{~h}$ of the termination of each trial to verify their individual 
identity. Experiments were conducted at $9.0 \pm 0.1^{\circ} \mathrm{C}$ in 1990 , and at $10.4 \pm 0.5^{\circ} \mathrm{C}$ in 1991.

Size predation trials, 1991: In each size predation trial a single sand shrimp was offered 2 winter flounder metamorphs as prey. The fish used were identical in age and from the same family (and, if possible, the same rearing aquaria), but differed in length. We chose the largest length difference that could be obtained consistently throughout the course of the experiment. We verified that the chosen size difference was sufficient for identification of individuals at the end of each trial. This was done by measuring individuals at time spans equivalent to the predation trials to confirm that growth during that period did not obscure previous size differences. We attempted to keep the length difference constant for all pairs of fish. To account for differences in the absolute size of pairs of metamorphs we report the percentage length difference within pairs of fish. Percentage length difference was calculated by dividing the absolute length difference between a pair of fish by the average length of the 2 fish and then multiplying by 100 . We also attempted to keep the prey/predator length ratio constant for all experimental pairs because the magnitude of this ratio is known to affect larval mortality rate in predation experiments (e.g. Miller et al. 1988, Pepin et al. 1992). Predator size was close to the modal size of shrimp present in situ during the time of winter flounder settlement in the field. Shrimp were collected by beach seining and allowed to acclimate to experimental conditions for 2 d before the trials commenced. During acclimation, predators were kept in containers which were identical to the experimental arena. Predators were not fed during this period in order to achieve a high initial hunger level during experiments.

Age predation trials, 1990: In each trial a single sand shrimp was offered a single metamorph as prey. The prey were all from the same family. Within a family winter flounder exhibit considerable variation in age at metamorphosis (Chambers \& Leggett 1987, Bertram et al. 1993). Predation trials were conducted throughout the entire range of ages at metamorphosis that was exhibited by the chosen family. On a given date, all of the metamorphs were identical in age. Predators were collected, held and selected in the manner outlined above.

Age predation trials, 1991: The experimental design for the age trials in 1991 was identical to that for the size predation trials with the exception that the 2 prey fish differed in age (referred to as 'young' and 'old') but not in size. We produced 2 groups of metamorphs which differed in age, by staggering hatching dates (see 'Rearing protocol' above). 'Young' metamorphs (stocked later) and 'old' metamorphs (stocked earlier) differed in age by $9 \mathrm{~d}$. 'Young' and 'old' individuals of the same length $( \pm 0.15 \mathrm{~mm})$ were then selected as experimental pairs. To account for differences in the absolute age of metamorphs with date, we report the percentage age difference within pairs of fish. Percentage age difference was calculated by dividing the absolute age difference between the individuals within a pair by the average age of these individuals and then multiplying by 100 . Individuals within each experimental pair were videotaped before trials; survivors were filmed following the trials. Individual variation in the pigmentation of the caudal region (filmed with the aid of dissecting microscope at $25 \times$ ) facilitated the identification of individual metamorphs. Survivors were identified by simultaneous comparison of video images of individuals taken before and after each trial. For all trials we attempted to maintain a constant length ratio between predator and prey (see above).

Statistical analyses. The outcomes of the predation trials (for both age and length at metamorphosis) were analyzed using a chi-square goodness of fit test. The results obtained were used to evaluate the null hypothesis of equal likelihood of death for 'young' and 'old' or 'small' and 'large' metamorphs. We report the power of statistical tests on our capture frequency data. Also given are the relevant parameters required to calculate power: effect size (ES; for the chi-squared analysis, ES measures the discrepancy between the observed and expected proportions of the number of small and large, or young and old, fish eaten; Cohen 1977), sample size $(n)$, and significance criterion $(\alpha)$. Note that $\beta$, the probability of making a type Il error, can easily be calculated once power is known (power $=1-\beta$ ).

We examined the frequency of captures in $4 \mathrm{~h}$ (1990) and $2 \mathrm{~h}$ (1991) intervals after the initiation of predation trials. To determine if older metamorphs survived longer in predation trials than younger fish we regressed time until capture on age at metamorphosis. For the 1991 data we combined the results from the age and size predation trials. The analysis was conducted using trials in which only 1 prey was consumed and again when trials in which both prey were consumed were included.

\section{RESULTS}

\section{Predation risk as a function of length}

In the length experiments, age was identical but prey length differed on average by $0.48 \mathrm{~mm}_{\text {; }}$ percentage length difference between pairs of prey averaged $7.7 \%$ (Table 1). Throughout the experiment the prey/predator length ratio remained roughly constant at 0.2 (Table 1). In 104 trials where only 1 prey was consumed 56 were 'small' and 48 were 'large' metamorphs (Fig. 1). Differ- 
Table 1. Crangon septemspinosa preying on Pleuronectes americanus. Summary statistics for the size predation trials. Pred.: predator; Diff.: difference between experimental pairs of fish

\begin{tabular}{|c|c|c|c|c|c|c|c|}
\hline & \multicolumn{3}{|c|}{ Fish length $(\mathrm{mm})$} & \multirow{2}{*}{$\begin{array}{l}\text { Length difference } \\
\qquad(\%)\end{array}$} & \multirow{2}{*}{$\begin{array}{c}\text { Fish age } \\
\text { (d) }\end{array}$} & \multirow{2}{*}{$\begin{array}{l}\text { Pred. length } \\
\qquad(\mathrm{mm})\end{array}$} & \multirow[t]{2}{*}{ Prey/pred. length ratio } \\
\hline & Small & Large & Diff. & & & & \\
\hline $\mathrm{n}$ & 145 & 145 & & 145 & 145 & $135^{\mathrm{b}}$ & $135^{\mathrm{b}}$ \\
\hline Min. & 4.96 & 5.44 & 0.24 & 3.6 & 38 & 24.8 & 0.18 \\
\hline Max. & 6.88 & 7.36 & 0.8 & 13.3 & 71 & 38.3 & 0.24 \\
\hline Mean & 6.15 & 6.64 & 0.49 & 7.7 & 56.5 & 31.4 & 0.20 \\
\hline $\mathrm{SD}$ & 0.29 & 0.27 & 0.08 & 1.4 & 10.4 & 2.3 & 0.01 \\
\hline
\end{tabular}

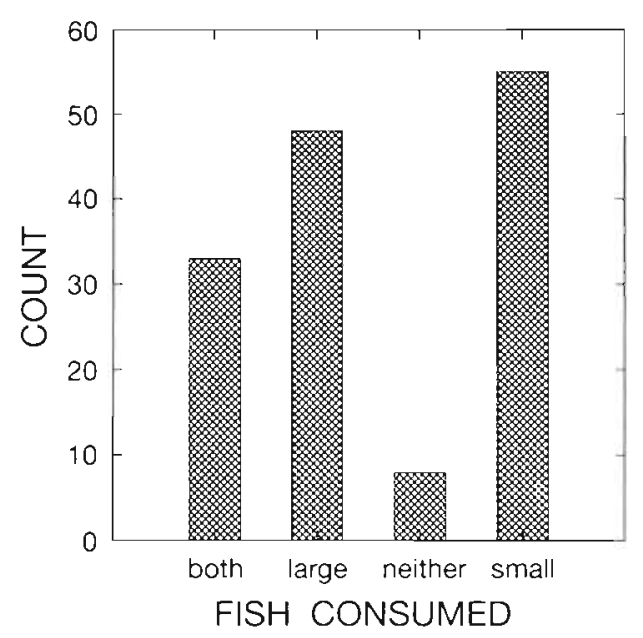

Fig. 1. Pleuronectes americanus. Capture frequency for pairs of prey in the size predation trials $(n=145)$. Categories refer to the fish from each trial which were consumed

ences in the experimental outcome were not related to differences in the prey/predator length ratio. Based on the chi-squared goodness of fit test we cannot conclude that large fish were consumed more frequently than small fish $\left[\chi^{2}=0.48, \mathrm{df}=1\right.$, not significant, $\alpha=0.05, \mathrm{n}=$ $103, \mathrm{ES}=0.068$, power $<0.17$ (based on $\mathrm{ES}=0.1$, the lowest value reported by Cohen 1977)].

\section{Predation risk as a function of age}

1990. Metamorphs in the predation trials averaged $6.75 \mathrm{~mm}$ (Table 2). Throughout the experiment the prey/predator length ratio remained roughly constant at 0.2 (Table 2). In 63 of the 74 trials conducted, the metamorph was consumed by the shrimp predator. In the remaining trials, 8 shrimp molted, 1 died, and 2 trials were halted (after 62 and $116 \mathrm{~h}$ ). Time until capture ranged from 1.5 to $240 \mathrm{~h}$. Thirty-three percent (21/63) of the captures occurred within the first $10 \mathrm{~h}$. Regression analysis indicated that time until capture (log-transformed) did not vary with age at metamorphosis ( $F=$ 0.069 , $\mathrm{df}=1,61, \mathrm{p}=0.794$ ). Moreover, variation in prey length and prey/predator length ratio did not influence that result. To achieve a comparison with the results from 1991, we reanalyzed the time until capture data using only those trials which ended in $40 \mathrm{~h}$ or less. We found no change in the general results: $29 \%$ of captures (15/51) occurred within the first $4 \mathrm{~h}$ (Fig. 2a). Furthermore, time until capture (log-transformed) did not vary ( $F=0.367, \mathrm{df}=1.41, \mathrm{p}=0.548$ ) with age at metamorphosis in the reduced data set (Fig. 2b).

1991. In the age experiments, length was virtually identical but prey differed in age by $9 \mathrm{~d}$ (Table 3); the percentage age difference between pairs of prey averaged $18 \%$. Throughout the experiment the prey/ predator length ratio remained roughly constant at 0.2 (Table 3 ). In 56 trials where only 1 prey was consumed 27 were 'young' and 29 were 'old' metamorphs (Fig. 3). Based on the chi-squared goodness of fit test we cannot conclude that 'old' fish were consumed more frequently than 'young' metamorphs $\left[\chi^{2}=0.07\right.$, df $=1$, not significant, $\alpha=0.05$, ES $=0.04$, power $<0.11$ (based on $\mathrm{ES}=0.1$, the lowest value reported by Cohen 1977)].

Table 2. Crangon septemspinosa preying on Pleuronectes americanus. Summary statistics for the 1990 age predation trials

\begin{tabular}{|lcccc|}
\hline & $\begin{array}{c}\text { Fish length } \\
(\mathrm{mm})\end{array}$ & $\begin{array}{c}\text { Fish age } \\
(\mathrm{d})\end{array}$ & $\begin{array}{c}\text { Pred. length } \\
(\mathrm{mm})\end{array}$ & $\begin{array}{c}\text { Prey/pred. } \\
\text { length ratio }\end{array}$ \\
\hline $\mathrm{n}$ & 74 & 74 & $71^{\mathrm{b}}$ & $71^{\mathrm{b}}$ \\
$\mathrm{Min}$ & 6.09 & 60 & 27.0 & 0.18 \\
$\mathrm{Max}$. & 7.34 & 97 & 36.1 & 0.24 \\
$\mathrm{Mean}$ & 6.75 & 78.2 & 33.1 & 0.20 \\
$\mathrm{SD}$ & 0.27 & 9.7 & 1.74 & 0.01 \\
\multicolumn{5}{|c}{} \\
a Prey length was based on the average length of the prey \\
in each experimental pair \\
b3 shrimp were lost between the end of the trial and the \\
time of measurement
\end{tabular}



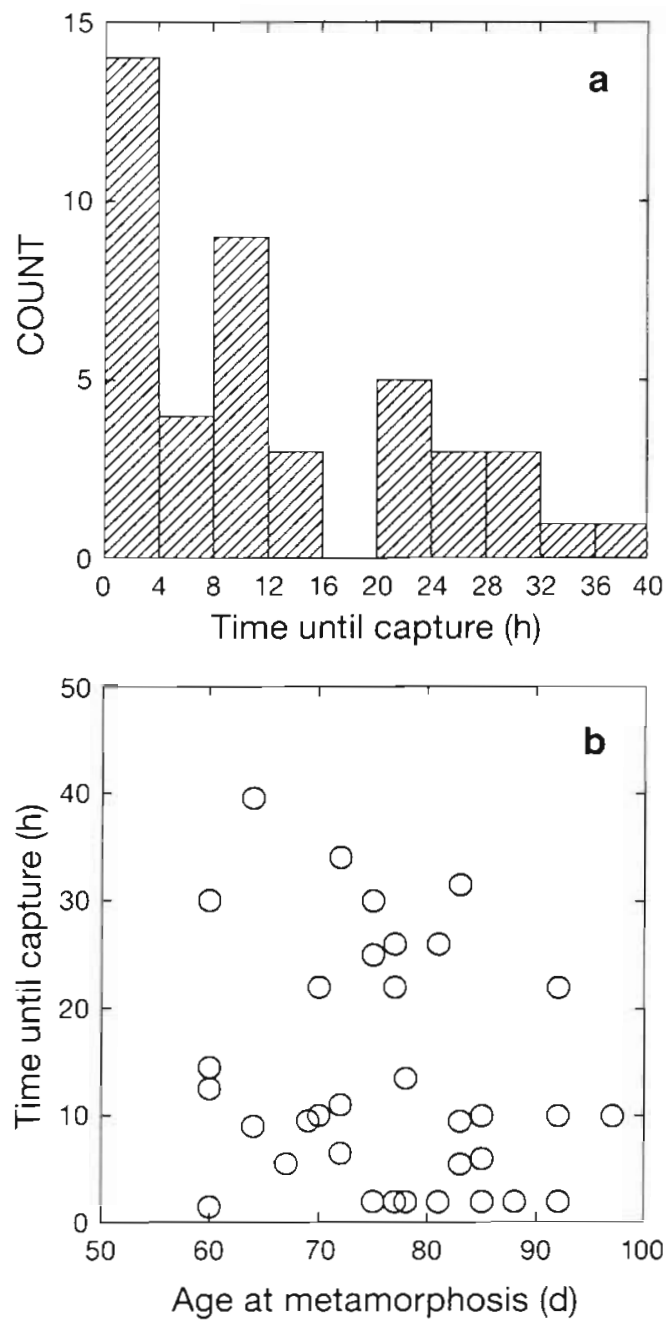

Fig. 2. Pleuronectes americanus. Predation trials in 1990. (a) Frequency of captures within $4 \mathrm{~h}$ intervals after the initiation of trials $(n=51)$. (b) Time until capture (untransformed) in relation to age at metamorphosis. Shown are captures that occurred in 40 h or less

In the age and size predation trials 66 and $52 \%$ of the captures occurred within the first $4 \mathrm{~h}$, respectively. When the age and size trial data sets were combined

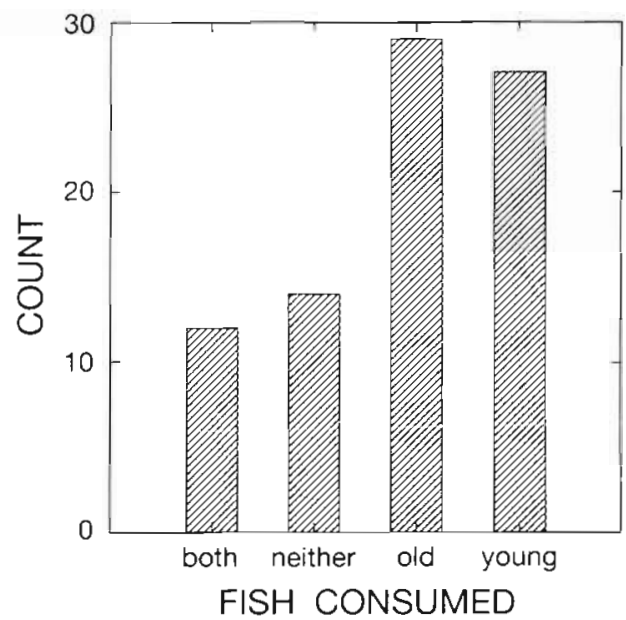

Fig. 3. Pleuronectes amenicanus. Capture frequency for pairs of prey in the 1991 age predation trials $(n=84)$. Categories refer to the fish from each trial which were consumed

37 and $57 \%$ of fish were captured within the first 2 and $4 \mathrm{~h}$, respectively (Fig. 4a). Time until capture (logtransformed) showed no trend with increasing age at metamorphosis for either the age or size trials ( $F=$ 0.143 , df $=1,158, p=0.705$, for the combined data sets; Fig. 4 b). The result was unaffected by variation in prey or prey/predator length ratio, or the inclusion of trials in which both fish were consumed.

\section{DISCUSSION}

\section{Predation risk for fish which vary in size}

The results show that fish which differ in length at metamorphosis have similar probabilities of being eaten by shrimp predators. Although no strictly comparable studies exist, 2 studies which employed protocols similar to those used in our experiment (Table 4) have examined predation risk for yolk sac and first feeding larvae. [The comparison of our study with the

Table 3. Crangon septemspinosa preying on Pleuronectes americanus. Summary statistics for the 1991 age predation trials

\begin{tabular}{|c|c|c|c|c|c|c|c|c|c|}
\hline & \multicolumn{3}{|c|}{ Fish length $(\mathrm{mm})$} & \multicolumn{3}{|c|}{ Fish age $(d)$} & \multirow{2}{*}{$\begin{array}{l}\text { Age diff. } \\
\text { (d) }\end{array}$} & \multirow{2}{*}{$\begin{array}{l}\text { Pred, length } \\
\quad(\mathrm{mm})\end{array}$} & \multirow[t]{2}{*}{ Prey/pred. length ratio ${ }^{\circ}$} \\
\hline & Young & Old & Diff. & Young & Old & Diff. & & & \\
\hline $\mathrm{n}$ & 84 & 84 & & 84 & 84 & 84 & 84 & $61^{\mathrm{b}}$ & $61^{b}$ \\
\hline Min. & 5.92 & 5.92 & 0.16 & 39 & 48 & 9 & 16 & 27.9 & 0.17 \\
\hline Max. & 7.20 & 7.20 & 0.32 & 52 & 61 & 9 & 21 & 36.9 & 0.23 \\
\hline Mean & 6.45 & 6.45 & 0.002 & 47.1 & 56.1 & 9 & 18 & 32.1 & 0.20 \\
\hline $\mathrm{SD}$ & 0.30 & 0.30 & 0.115 & 4.2 & 4.2 & 0 & 1.5 & 2.0 & 0.01 \\
\hline
\end{tabular}



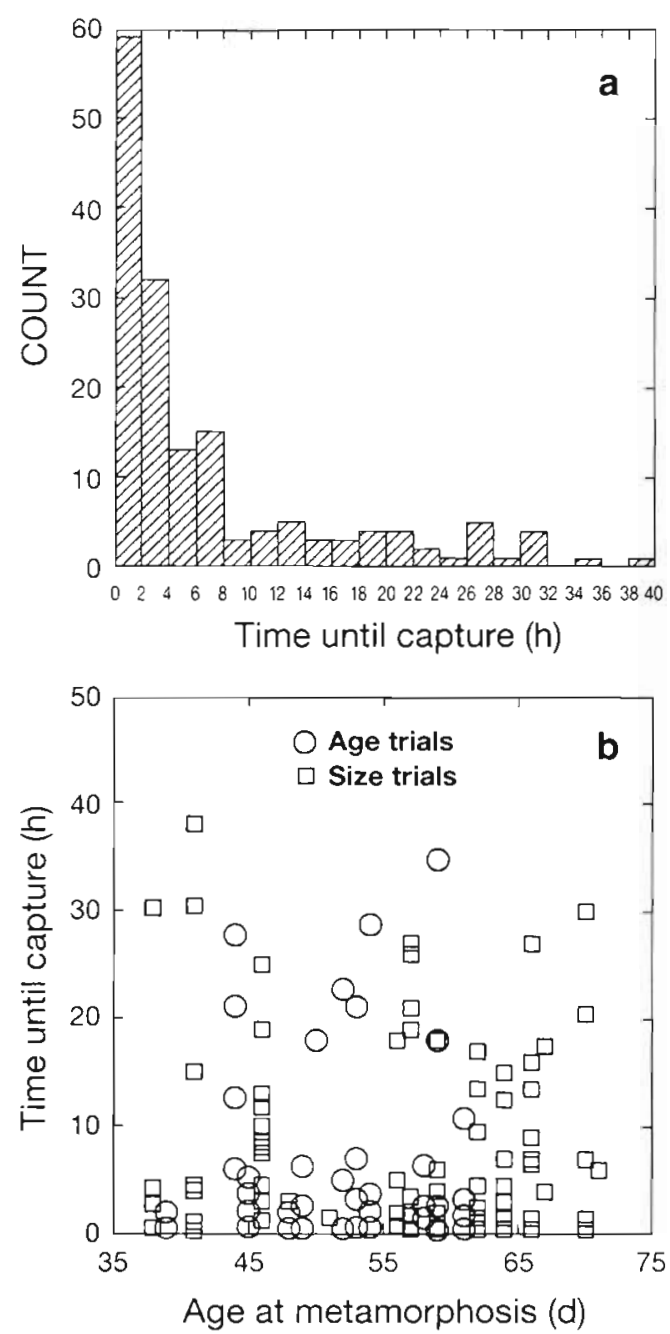

Fig. 4. Pleuronectes americanus. Predation trials in 1991 (a) Frequency of captures within $2 \mathrm{~h}$ intervals after the initiation of trials ( $n=104$ ). (b) Time until capture (untransformed) in relation to age at metamorphosis for the size and age predation trials. Shown are trials in which only 1 prey was consumed

studies listed in Table 4 is reasonable because previous comparative work has shown that capture success of fish larvae does not differ for invertebrate and vertebrate predators; Pepin et al. (1987), Miller et al. (1988). Furthermore, both shrimp and stickleback are active predators.] Both studies report that when offered prey which varied in length, predators consumed greater numbers of large larvae. Litvak \& Leggett (1992) obtained this result for both active (vertebrate) and passive (invertebrate) predators. It is unlikely that the difference in outcome between our study and those reported in Table 4 resulted from differences in the prey/predator size ratio or the magnitude of the size differences between small and large prey items employed in the various studies. Using the general model for the relationship between capture success and the ratio of predator to prey length established by Miller et al. (1988) we show that the difference in the capture probability for small and large larvae was more than twice as large in our study as in the study by Litvak \& Leggett (1992; Table 4). Despite having smaller differences in prey size and a larger predator relative to prey size, Litvak \& Leggett (1992) found significant differences in vulnerability to predation for small and large prey. Even though the size difference between the small and large prey was relatively large, and the predator was relatively small in our experiments, we could not detect a difference in predation risk for small and large prey. We conclude that there is no clear survival advantage for fish which are relatively large-at-age at metamorphosis.

An important conclusion resulting from this study is that when age is controlled, estimates of predationinduced mortality rates based on size-dependent models can be inflated. We illustrate this point using the following equation provided by Pepin et al. (1992) for calculating the instantaneous daily mortality rate for capelin larvae based on the lengths of the prey and the predator:

$$
Z=13.9-2.58 L_{l}+0.046 L_{\mathrm{p}}
$$

where $L_{1}=$ length of capelin larvae and $L_{p}=$ length of the predator. The inputs to the vulnerability equation are intended to be comparable to the size classes of prey and predator used in our study and to those used by Litvak \& Leggett (1992) and Pepin et al. (1992). The equation predicts that a prey of length $5.0 \mathrm{~mm}$ would sustain a mortality rate 1.5 times higher than a prey of length $5.5 \mathrm{~mm}$ when each group was offered to a predator of $50 \mathrm{~mm}$ (the mean predator length from the study of Pepin et al. (1992) was $47.9 \pm 8.4 \mathrm{~mm}$; P. Pepin unpubl. data]. Note that the model results do not agree with the empirical results of the studies where size was varied but age was held constant (Table 4): Litvak \& Leggett (1992) and Pepin et al. (1992) found that smaller larvae had higher survival within trials in which age was held constant. Our study could not detect a difference in mortality for small and large fish. Thus, while larger, older larvae typically experience a lower predation mortality than smaller, younger larvae (e.g. Folkvord \& Hunter 1986, Pepin et al. 1992), we suggest that large size is unlikely to be consistently superior when larvae of the same age are compared. If our results and those of Litvak \& Leggett (1992) and Pepin et al. (1992) are general, small differences in prey size may have different consequences for predation mortality when age is controlled than would be predicted from size-based models which do not account for variation in prey size-at-age. To avoid biased estimates of instantaneous mortality rates, future models should attempt to discriminate between 
Table 4. Outcome and protocol of studies which examined predation risk for fish which varied in length but not in age. Average values for lengths are reported unless otherwise stated. The difference in the probability of capture ( $P_{\text {capture, }}$ calculated using the general model of Miller et al. (1988): $100-[(\mathrm{R}+3.37) / 44.76]^{-2.28}$, where $\mathrm{R}=$ predator/prey length ratio) for large and small larvae is also compared between studies

\begin{tabular}{|c|c|c|c|c|c|c|c|c|}
\hline \multirow[t]{2}{*}{ Prey and pred. } & \multicolumn{2}{|c|}{$\begin{array}{l}\text { Prey length } \\
(\mathrm{mm})\end{array}$} & \multirow{2}{*}{$\begin{array}{l}\text { Pred. } \\
\text { length } \\
(\mathrm{mm})\end{array}$} & \multirow{2}{*}{$\begin{array}{l}\text { Prey/pred. } \\
\text { length } \\
\text { ratio }\end{array}$} & \multirow{2}{*}{$\begin{array}{c}\text { Prey } \\
\text { length } \\
\text { diff. }(\%)\end{array}$} & \multirow[t]{2}{*}{ Outcome } & \multirow{2}{*}{$\begin{array}{l}\text { Diff. in } P_{\text {capture }} \\
\text { for small and } \\
\text { large prey }(\%)\end{array}$} & \multirow[t]{2}{*}{ Source } \\
\hline & Small & Large & & & & & & \\
\hline $\begin{array}{l}\text { Capelin and } \\
\text { stickleback }\end{array}$ & $4.94^{\mathrm{a}}$ & $5.22^{\mathrm{a}}$ & 38 & 0.13 & 5.6 & $\begin{array}{l}\text { Larger larvae } \\
\text { selected }\end{array}$ & 2.2 & $\begin{array}{l}\text { Litvak \& Leggett (1992) } \\
\text { laboratory expt \#2 }\end{array}$ \\
\hline $\begin{array}{l}\text { Capelin and } \\
\text { stickleback }\end{array}$ & $--^{b}$ & $-\mathrm{b}$ & $36-61^{c}$ & $0.08-0.16$ & $--^{d}$ & $\begin{array}{c}\text { Larger larvae } \\
\text { selected within trials }\end{array}$ & - & Pepin et al. (1992) \\
\hline $\begin{array}{l}\text { Winter flounder } \\
\text { and shrimp }\end{array}$ & 6.15 & 6.64 & 31.4 & 0.20 & 7.7 & $\begin{array}{l}\text { Equal selection of } \\
\text { small and large } \\
\text { metamorphs }\end{array}$ & 4.9 & This study \\
\hline \multicolumn{9}{|c|}{$\begin{array}{l}{ }^{a} \mathrm{M} \text {. Litvak (unpubl. data) } \\
{ }^{\mathrm{b}} \text { Prey ranged from } 5.0 \text { to } 5.8 \mathrm{~mm} \text { (P. Pepin unpubl. data) } \\
{ }^{c} \text { P. Pepin (unpubl. data) } \\
{ }^{\mathrm{d}} \text { Each predator was offered a cohort of similar-aged cape } \\
\mathrm{n}=23 \text {; mean } \pm \mathrm{SD} \text { of } \mathrm{SDS}=0.598 \pm 0.111, \mathrm{n}=23_{;} \text {P. Pep }\end{array}$} \\
\hline
\end{tabular}

fishes which vary in both size and age, and those fish which vary in size at a given age.

\section{Predation risk for fish which vary in age}

The experiments reported here are the first to examine vulnerability to predation in relation to variation in age, independent of length effects. We cannot conclude, however, that 'old' fish were eaten more frequently than 'young' metamorphs (Fig. 3). This finding is supported by the discovery that, in both years, the time until death in predation trials did not increase with increasing age at metamorphosis (Figs. $2 b$ \& 4 b), despite the fact that the entire range of ages at metamorphosis was represented (approx. $35 \mathrm{~d}$ ). The results suggest that there is no benefit, in terms of reduced predation mortality at metamorphosis, for larvae which experience relatively long larval durations and hence metamorphose at older ages.

\section{Statistical versus ecological significance}

Peterman (1990) argued that statistical power analysis can improve the interpretation of biological data used in fisheries research and management. For studies which fail to reject a null hypothesis, Peterman (1990) recommends that $\beta$, the probability of making a type II error (not rejecting a null hypotheses when it is false) and statistical power $(1-\beta)$, should be routinely reported. Statistical power is the probability of reject- ing a null hypothesis when it is false - it can also be thought of as the probability that a statistical test will yield statistically significant results (Cohen 1977). In our study, statistical power analysis was used to explore the ability of the experimental design we used to detect differences in predation risk in relation to variation in length or age at metamorphosis. The statistical power of a test can be calculated when the significance criterion $(\alpha)$, the sample size (n) and the effect size (ES) are known. (Note that ES can only be estimated after an experiment has been run.) ES was low $(<0.1)$ in both of the predation experiments we performed. This low ES contributed to the low statistical power of the chi-square tests.

Cohen (1977) suggests that, for comparative purposes, authors may wish to report a 'comparable detectable effect size' given at a fixed level of statistical power (e.g. 0.5). In this study, we would have required 830 and 2963 trials to detect differences in the size and age predation experiments, respectively at a power of 0.5, given the ES values observed. However, had the effect sizes between the experimental groups been greater, our experiments would have been much more likely to find statistical significance given the reasonably large number of trials conducted. For example, in the 104 size-based predation trials, a doubling of ES to 0.2 would result in a 3 -fold increase in power $(0.5)$. Similarly, the 56 age predation trials conducted could detect an ES of 0.28 with a statistical power of 0.5 . These analyses demonstrate that the ES exhibited for the traits examined were exceedingly small, and that this factor was central in the failure to 
statistically differentiate the effects of predation on size and age. However, the above calculations also highlight the point that statistical significance can always be achieved if sufficient samples are collected. Had we conducted the number of trials required to yield statistical significance, we would, in effect, have demonstrated a very weak biological effect. The important conclusion of our experiments is that the low ES values indicate that any differences in predation risk between fish which exhibit the range of ages and sizes at metamorphosis represented in our experiments, are subtle and are potentially inconsequential from an ecological perspective. Nonetheless, the ES estimates we report for vulnerability to predation in relation to age and length at metamorphosis can be used as a basis for the design of future experiments which address size- and age-dependent predation risk.

\section{Use of cross-sectional versus longitudinal data}

We developed cross-sectional data (which examines a trait at a single point during the ontogeny of an individual) and used these to infer that the ecological effects of any differences in predation risk which exist between fish which differ in age and size at metamorphosis are likely to be subtle and potentially inconsequential. It could, however, be argued that even small survival differences between phenotypes can be important because of their cumulative effects over time. For example, if fish which are larger-at-age have a slight survival advantage at successive stages of development, the benefits of large size would accumulate over time. However, survival benefits would only accumulate if the ranking of size-at-age within a cohort remained consistent over time, and if larger fish consistently had a survival advantage. Recent studies on larval and juvenile winter flounder suggest that the size-at-age rankings within a cohort may change as development proceeds (Bertram et al. 1993). In addition, recent experiments on selection for vertebral number of larval stickleback have demonstrated that the direction of selection can change during ontogeny. Swain (1992b) demonstrated that selection on vertebral number (a component of fitness; Swain 1992a) involving a single selective agent (piscivore predation) could be reversed at only slight differences in larval body length (approximately $1 \mathrm{~mm}$ ). Swain (1992b) pointed out that, when the direction of selection changes during ontogeny (see also Atchley 1984), phenotypic variability will be favored and thus maintained. Longitudinal data examine the value of a trait at successive intervals throughout the ontogeny of individuals and thus facilitate separation of size and age effects. Such data are required to determine if the cumulative probability of survival during early life varies for individuals with different size-at-age trajectories (i.e. growth rates) within a cohort. To date, however, no such studies of fishes have experimentally evaluated the cumulative probability of predation mortality in a longitudinal fashion. Hence, there is, at present, no firm support for the argument that being larger, or smaller, at age is superior. The development of such studies represents a challenge for future investigations of predation as an agent of selection on the early life history traits of fishes.

Acknowledgements. We thank the staff at the Huntsman Marine Science Centre (HMSC) and, in particular, M. Litvak and $F$. Purton for their cooperation in this research. Additional logistic support and technical advice were kindly provided by D. Bengsten, J. Brown, C. Chambers, C. Couturier, M. Goldstein, G. Maillet, D. Martin-Robichaud, J. Nielson, P. Pearly, and R. Rangley. J. Farrell, S. Gutterman, N. Roy, K. Tallon, $\mathrm{S}$. Whelan, and U. Voitk provided tireless technical assistance. P. Pepin and M. Litvak graciously provided unpublished data. We thank $T$ Miller and 2 anonymous reviewers for constructive criticisms and helpful suggestions. Financial support was provided by Natural Sciences and Engineering Research Council (NSERC) of Canada operating and strategic grants to W.C.L. Additional financial support was provided by a NSERC Postgraduate Scholarship, the Anne Vallée Ecological Fund Scholarship, a HMSC Graduate Fellowship, and a GIROQ stipend to D.F.B.

\section{LITERATURE CITED}

Anderson, J. T. (1988). A review of size dependent survival during pre-recruit stages of fishes in relation to recruitment. J. Northw. Atlant. Fish. Sci. 8: 55-66

Atchley, W. R. (1984). Ontogeny, timing of development, and genetic variance-covariance structure. Am. Nat. 123: $519-540$

Bailey, K. M., Houde, E. D. (1989). Predation on eggs and larvae of marine fishes and the recruitment problem. Adv. mar. Biol. 25: 1-83

Bergman, M. J. N, van der Veer, H. W. Zijlstra, J. J. (1989). Plaice nurseries: effects on recruitment. J. Fish. Biol. 33: $201-218$

Bertram, D. F., Chambers, R. C., Leggett, W. C. (1993). Negative correlations between larval and juvenile growth rates in winter flounder: the implications of compensatory growth for variation in size-at-age. Mar. Ecol. Prog. Ser. 96: $209-215$

Beyer, J. (1989). Recruitment stability and survival: simple size-specific theory with examples from the early life dynamics of marine fish. Dana 7: 45-147

Chambers, R. C., Leggett, W. C. (1987). Size and age at metamorphosis in marine fishes: an analysis of laboratoryreared winter flounder (Pseudopleuronectes americanus) with a review of variation in other species. Can. J. Fish. Aquat. Sci. 44: 1936-1947

Cohen, J. (1977). Statistical power analysis for the behavioural sciences. Academic Press, New York

Crowder, L. B., Rice, J. A., Miller, T. J., Marschall, E. A. (1992). Empirical and theoretical approaches to size-based interactions and recruitment variability in fishes. In: DeAngelis, D. L., Gross L. J. (eds.) Individual-based mod- 
els and approaches in ecology: populations, communities, and ecosystems. Chapman and Hall, New York, p. $237-255$

Folkvord, A.. Hunter, J R. (1986). Size-specific vulnerability of northern anchovy, Engraulis mordax, larvae to predation by fishes. Fish. Bull. U.S. 84: 859-869

Fuiman, L. A. (1989). Vulnerability of Atlantic herring larvae to predation by yearling herring. Mar. Ecol. Prog. Ser. 51: 291-299

Houde, E. D. (1987). Fish early life dynamics and recruitment variability. Am. Fish. Soc. Symp. 2: 17-29

Jeffries, H. P., Terceiro, M. (1985). Cycle of changing abundances in the fishes of the Narragansett Bay area. Mar. Ecol. Prog. Ser. 25: 239-244

Litvak, M. K., Leggett, W. C. (1992). Age and size-selective predation on larval fishes: the bigger-is-better hypothesis revisited. Mar. Ecol. Prog. Ser. 81; 13-24

Luecke, C., Rice, J. A., Crowder, L. B., Yeo, S. E., Binkowski, F. P. (1990). Recruitment mechanisms in lake Michigan; an analysis of the predatory gauntlet. Can. J. Fish. Aquat. Sci. 47: $524-532$

McGurk, M. D. (1986). Natural mortality of marine pelagic fish eggs and larvae: role of spatial patchiness. Mar. Ecol. Prog. Ser. 34: 227-242

Miller, T. J., Crowder, L. B., Rice, J. A., Marschall, E. A. (1988). Larval size and recruitment mechanisms in fishes: toward a conceptual framework. Can. J. Fish. Aquat. Sci. 45: $1657-1670$

O'Brien, W. J. (1979). The predator-prey interaction of planktivorous fish and zooplankton. Am. Scient. 67: 572-581

Pepin, P. (1989a). Predation and starvation of larval fish: a numerical experiment of size- and growth-dependent survival. Biol. Oceanogr. 6: 23-44

Pepin, P. (1989b) Using growth histories to estimate larval fish mortality rates. Rapp. P.-v. Réun. Cons. int. Explor. Mer 191: $324-329$

Pepin, P., Pearre, S. Jr, Koslow, J. A. (1987). Predation on larval fish by Atlantic mackerel, Scomber scombrus, with a comparison of predation by zooplankton. Can. J. Aquat. Sci. 44: 2012-2018

Pepin, P., Shears, T H., de Lafontaine, Y. (1992). Significance of body size to the interaction between a larval fish ( $M a l-$ lotus villosus) and a vertebrate predator (Gasterosteus aculeatus). Mar. Ecol. Prog. Ser. 81: 1-12

Peterman, R. M. (1990). Statistical power analysis can

This article was submitted to the editor improve fisheries research and management. Can. J. Fish. Aquat. Sci. 47: 2-15

Rice, J. A., Crowder, L. B., Holey, M. E. (1987). Exploration of mechanisms regulating larval survival in Lake Michigan bloater: a recruitment analysis based on characteristics of individual larvae. Trans. Am. Fish. Soc. 116: 703-718

Rice, J. A, Miller, T. J., Rose, K. A., Crowder, L. B., Marschall, E. A., Trebitz, A. S., DeAngelis, D. L. (1993). Growth rate variation and larval survival: inferences from an individual-based size-dependent predation model. Can. J. Fish. Aquat. Sci. 50: 133-142

Ricklefs, R. E. (1973). Patterns of growth in birds. II. Growth rate and mode of development. Ibis 115: 177-201

Ricklefs, R. E. (1979a). Adaptation, constraint, and compromise in avian postnatal development. Biol. Rev. Cambridge Philos. Soc. 54: 269-290

Ricklefs, R. E. (1979b). Patterns of growth in birds. V. A comparative study of development in the starling, common tern and Japanese quail. Auk 96: 10-30

Seikai, T., Kinoshita, I., Tanaka, M. (1993). Predation by crangonid shrimp on juvenile Japanese flounder under laboratory conditions. Nippon Suisan Gakk. 59: 321-326

Swain, P. (1992a). The functional basis of natural selection for vertebral traits of larvae in the stickleback (Gasterosteus aculeatus). Evolution 46: 998-1013

Swain, P. (1992b). Selective predation for vertebral phenotype in Gasterosteus aculeatus: reversal in the direction of selection at different larval sizes. Evolution 46: 998-1013

van der Veer, H. W. Bergman, M. J. N. (1987). Predation by crustaceans on a newly settled 0-group plaice Pleuronectes platessa population in the western Wadden Sea. Mar. Ecol. Prog. Ser. 35: 203-215

van der Veer, H. W., Bergman, M. J. N., Dapper, R., Witte, J. IJ. (1991). Population dynamics of an intertidal 0-group flounder Platichthys flesus population in the western Dutch Wadden Sea. Mar. Ecol. Prog. Ser 73: 141-148

van der Veer, H. W., Pihl, L. Bergman, M. J. N (1990). Recruitment mechanisms in North Sea plaice Pleuronectes platessa. Mar. Ecol. Prog. Ser. 64: 1-12

Wilcox, J. R., Jeffries, H. P. (1974). Feeding habits of the sand shrimp Crangon septemspinosa. Biol. Bull. 146: 424-434

Williams, P. J., Brown, J. A. (1992). Developmental changes in the escape response of larval winter flounder (Pleuronectes americanus) from hatch through metamorphosis. Mar. Ecol. Prog. Ser, 88: 185-193

Manuscript first received: June 21, 1993

Revised version accepted: March 17, 1994 